\title{
The influence of pharmacologically-induced affective states on attention bias in sheep
}

\author{
Jessica E. Monk ${ }^{\text {Corresp., 1, 2, } 3}$, Caroline Lee $^{\text {Corresp., } 1}{ }^{1}$, Sue Belson ${ }^{1}$, Ian G. Colditz ${ }^{1}$, Dana L. M. Campbell ${ }^{1}$ \\ ${ }^{1}$ Agriculture and Food, CSIRO, Armidale, NSW, Australia \\ 2 School of Environmental and Rural Science, University of New England, Armidale, NSW, Australia \\ 3 Sheep CRC, University of New England, Armidale, NSW, Australia \\ Corresponding Authors: Jessica E. Monk, Caroline Lee \\ Email address: jessica.monk@csiro.au, caroline.lee@csiro.au
}

When an individual attends to certain types of information more than others, the behavior is termed an attention bias. The occurrence of attention biases in humans and animals can depend on their affective states. Based on evidence from the human literature and prior studies in sheep, we hypothesized that an attention bias test could discriminate between pharmacologically-induced positive and negative affective states in sheep. The test measured allocation of attention between a threat and a positive stimulus using key measures of looking time and vigilance. Eighty 7-year-old Merino ewes were allocated to one of four treatment groups; Anxious (m-chlorophenylpiperazine), Calm (diazepam), Happy (morphine) and Control (saline). Drugs were administered 30 min prior to attention bias testing. The test was conducted in a $4 \times 4.2 \mathrm{~m}$ arena with high opaque walls. An approximately life-size photograph of a sheep was positioned on one wall of the arena (positive stimulus). A small window with a retractable opaque cover was positioned on the opposite wall, behind which a dog was standing quietly (threat). The dog was visible for $3 \mathrm{~s}$ after a single sheep entered the arena, then the window was covered and the dog was removed. Sheep then remained in the arena for $3 \mathrm{~min}$ while behaviors were recorded. Key behaviors included time looking towards the dog wall or photo wall, duration of vigilance behavior and latency to become non-vigilant. In contrast with our hypothesis, no significant differences were found between treatment groups for duration of vigilance or looking behaviors, although Anxious sheep tended to be more vigilant than Control animals $(P<0.1)$ and had a longer latency to become non-vigilant $(P<0.001)$. Twenty-four of 80 animals were vigilant for the entire test duration. This censoring of data may explain why no differences were detected between groups for vigilance duration. Overall, a lack of difference between groups may suggest the test cannot discriminate positive and negative states in sheep. We suggest that the censoring of vigilance duration data, the use of insufficient drug doses, the potential influence of background noise and the age of the 
sheep may explain a lack of difference between groups. Due to these potential effects, it remains unclear whether the attention bias test can detect positive states in sheep. 
1 The influence of pharmacologically-induced affective states

2 on attention bias in sheep

3

4

5

6

7

8

Jessica E. Monk ${ }^{1,2,3}$, Caroline Lee ${ }^{1}$, Sue Belson ${ }^{1}$, Ian G. Colditz ${ }^{1}$, Dana L. M. Campbell ${ }^{1}$

${ }^{1}$ Agriculture and Food, CSIRO, Armidale, NSW, Australia

${ }^{2}$ School of Environmental and Rural Science, University of New England, Armidale, NSW, Australia

${ }^{3}$ Sheep CRC, University of New England, Armidale, NSW, Australia

Corresponding Author:

Jessica E. Monk ${ }^{1,2,3}$

FD McMaster Laboratory Chiswick, New England Hwy, Armidale, NSW, 2350, Australia Email address: jessica.monk@csiro.au

\section{Abstract}

When an individual attends to certain types of information more than others, the behavior is termed an attention bias. The occurrence of attention biases in humans and animals can depend on their affective states. Based on evidence from the human literature and prior studies in sheep, we hypothesized that an attention bias test could discriminate between pharmacologicallyinduced positive and negative affective states in sheep. The test measured allocation of attention between a threat and a positive stimulus using key measures of looking time and vigilance. Eighty 7-year-old Merino ewes were allocated to one of four treatment groups; Anxious (mchlorophenylpiperazine), Calm (diazepam), Happy (morphine) and Control (saline). Drugs were administered $30 \mathrm{~min}$ prior to attention bias testing. The test was conducted in a $4 \times 4.2 \mathrm{~m}$ arena with high opaque walls. An approximately life-size photograph of a sheep was positioned on one wall of the arena (positive stimulus). A small window with a retractable opaque cover was positioned on the opposite wall, behind which a dog was standing quietly (threat). The dog was visible for $3 \mathrm{~s}$ after a single sheep entered the arena, then the window was covered and the dog was removed. Sheep then remained in the arena for 3 min while behaviors were recorded. Key behaviors included time looking towards the dog wall or photo wall, duration of vigilance behavior and latency to become non-vigilant. In contrast with our hypothesis, no significant differences were found between treatment groups for duration of vigilance or looking behaviors, although Anxious sheep tended to be more vigilant than Control animals $(\mathrm{P}<0.1)$ and had a longer latency to become non-vigilant $(\mathrm{P}<0.001)$. Twenty-four of 80 animals were vigilant for the entire test duration. This censoring of data may explain why no differences were detected between groups for vigilance duration. Overall, a lack of difference between groups may suggest the test cannot discriminate positive and negative states in sheep. We suggest that the censoring of vigilance duration data, the use of insufficient drug doses, the potential influence of background noise and the age of the sheep may explain a lack of difference between groups. Due 
41 to these potential effects, it remains unclear whether the attention bias test can detect positive

42 states in sheep.

43

\section{Introduction}

45 The assessment of attention biases in non-human animals may allow us to gain a better understanding of the underlying affective states that relate to their welfare. An attention bias occurs when an animal attends to certain types of information before or for longer than others. Attention biases are determined by the salience of the information, or its perceived importance to the individual, and can be influenced by the animal's transient emotional states and sustained by moods. For example, humans in anxious states pay more attention towards threatening information than non-anxious individuals (Bradley et al., 1995; Bradley, Mogg \& Lee, 1997; Bar-Haim et al., 2007). Based on this principle, studies were conducted to determine whether an attention bias test developed for sheep was sensitive to changes in anxiety-like states (Lee et al., 2016; Monk et al., 2018b). The test measured time allocation of attention between a dog (threat) and a food reward (positive). The studies found that sheep in a pharmacologically-induced anxious state paid more attention towards the threat, evidenced by an increase in time spent looking towards the previous location of the dog and increased vigilance behavior compared to control animals. Further, sheep in an induced anxious state were less likely to feed than control animals. In comparison with controls, an induced calm state reduced time looking towards the threat, decreased vigilance and increased likeliness to feed. These results suggested the test could be used to assess anxious affective states in sheep. It remained unclear whether the pharmacological treatments modelled transient states or long term moods, and whether the test could differentiate these types of states. Hereafter, we use the term affective states to encompass both transient emotions and moods.

The attention bias test for sheep was later modified by replacing the food with a photograph of a conspecific, to remove the potential influence of appetite on animal behavior (Monk et al., 2018a). In the modified method, sheep in pharmacologically-induced anxious and depressed states were more vigilant than control animals. However the anxious group showed an attention bias towards the photograph rather than the threat. This unexpected result was attributed to the social aspect of the alternative positive stimulus and highlighted a need for context specific interpretations of behavioral responses. It appeared that within the context of the modified method, vigilance and exploratory behaviors, such as latency to sniff the environment, could be used to determine whether an animal was in a more negatively valenced affective state. The direction of attention could be used to discriminate anxious and depressed states from a neutral state. Although the interpretation of responses changed between test methods, each study demonstrated that an attention bias test could be used to assess and differentiate contrasting affective states in sheep, thus providing a new approach for researchers to better understand the affective states of livestock. 
81

82

83

84

85

86

87

88

89

90

91

92

93

94

95

96

97

98

99

100

101

102

103

104

105

106

107

108

109

110

111

112

113

114

115

116

117

118

119

120

While many animal studies have focused on reducing the occurrence of negative affective states, the presence of positive affective states also comprises an important, but relatively understudied component of animal well-being (de Vere \& Kuczaj, 2016). A number of human studies have demonstrated attention biases towards rewarding stimuli in subjects experiencing positive moods (e.g. Tamir \& Robinson, 2007; Grafton, Ang \& MacLeod, 2012; Sanchez \& Vazquez, 2014; Caudek, Ceccarini \& Sica, 2017), although these results have not been consistent in all tested populations (Isaacowitz et al., 2008). In sheep, Lee et al. (2016) and Monk et al. (2018b) demonstrated that the anxiolytic drug diazepam induced an attention bias away from a threatening stimulus and towards a food reward compared to saline treated control animals. This suggests that the attention bias test may be used to assess positive, or at least less negative, affective states in sheep. However, it could not be confirmed whether increased attention towards the food was due to the induced affective state or an increase in appetite caused by the drug (Foltin, 2004; Gaskins, Massey \& Ziccardi, 2008). The influence of a non-negative affective state on behavior in the modified attention test has not yet been established.

Pharmacological agents can be useful for modelling different types of affective states in animals, in a more standardized and repeatable manner than many environmental manipulations (Mendl et al., 2009; Doyle et al., 2015). Further, drugs can be used that remain active for the duration of testing, and provide information on the mechanisms and pathways underpinning animal behavior. Few studies have used pharmacological treatments in sheep to induce and assess positive affective states. The anxiolytic drug diazepam was used to reduce anxiety-like behaviors during development of the original attention bias test method (Lee et al., 2016; Monk et al., 2018b). Further, it has been used to reduce anxiety-like behaviors in a range of other contexts, such as during isolation and suddenness tests (e.g. Drake, 2006; Destrez et al., 2012). It has also been shown to attenuate stress-induced hyperthermia in other species, consistent with a less anxious state (Olivier et al., 2003; Bouwknecht, Olivier \& Paylor, 2007; Lee et al., 2017). However, for each of these studies it is difficult to determine whether the state induced by diazepam was truly positive as opposed to neutral or simply less negative than the other treatments. Verbeek et al. (2014) used the opioid agonist morphine to induce a positive affective state in sheep, due to its association with feelings of euphoria in humans (Riley et al., 2010). In sheep, the drug was found to enhance an optimistic judgement bias observed after feeding, consistent with having induced a more positive affective state (Verbeek et al., 2014). Therefore, morphine may be a useful pharmacological agent for confirming whether an attention bias test can discriminate euphoric-like positive affective states in sheep.

The aim of the current study was to determine whether the modified attention bias test could discriminate between positive and negative affective states in sheep. Specifically, we aimed to compare a high-anxiety state (Anxious), a low-anxiety state (Calm), a euphoric-like state

Peer) reviewing PDF | (2019:02:34955:2:0:NEW 24 Apr 2019) 
121 (Happy) and controls, induced using the drugs m-chlorophenylpiperazine, diazepam, morphine 122 and saline respectively. We hypothesized that the Anxious group would be more vigilant than 123 control animals while the Calm and Happy groups would be less vigilant, in line with previous

124

125

126

127

128

129

130

131

132

133

134

135

136

137

138

139

140

141

142

143

144

145

146

147

148

149

150

151

152

153

154

155

156

157

158

159

160

studies (Lee et al., 2016; Monk et al., 2018a,b). Further, we hypothesized that the Anxious group would show an increased body temperature response to the injection and would spend more time looking towards the positive stimulus during testing (photograph of a conspecific), as shown by Monk et al. (2018a). Given the differences in interpretation of behavioral responses between the original and modified test methods, it was difficult to predict the direction of attention for the Calm and Happy groups. However, our preliminary hypothesis was that they would both also pay more attention towards the positive stimulus (photo), in line with the human literature. We did not have an a priori hypotheses for how the Calm and Happy groups might differ from one another in vigilance or attention paid to the dog or photo. However we did expect these groups would differ in behavioral measures of arousal such as activity and vocalizations, with the Happy group showing signs of a higher arousal state than the other groups, consistent with previous studies (Verbeek et al., 2012, 2014).

\section{Materials \& Methods}

\section{Animal Ethics}

The protocol and conduct of the experiments were approved by the CSIRO F.D. McMaster Laboratory Animal Ethics Committee (AEC18-17), under the New South Wales Animal Research Act 1985.

\section{Experimental design}

To test whether the attention bias test could differentiate between different types of affective states, drugs were used to pharmacologically induce contrasting positive and negative affective states in ewes prior to testing. Specifically, drugs were used to induce high-anxiety states (Anxious), low-anxiety states (Calm), euphoric-like states (Happy) and control states (Control).

Eighty Merino ewes were weighed and randomly distributed between the treatment groups balancing for bodyweight. Sheep then had numbers painted on their wool for individual identification and were divided into two cohorts ( $n=40$ per group) to be tested on separate days for logistical reasons. Treatment groups were evenly distributed between the two cohorts. All injections and tests for the 40 animals studied on a given day, occurred between 8:00 am and 1:30 pm. The experiment was conducted during October 2018.

\section{Animal details}

The sheep used in this experiment were non-lactating, non-pregnant Merino ewes, approximately 7 years old, with average bodyweight of $47.0 \pm 5.4 \mathrm{~kg}$. Sheep were managed extensively throughout their life and were kept at pasture prior to testing. Sheep had prior experience with 
161 dogs during routine on-farm management when being moved between paddocks and handling

162

163

164

165

166

167

168

169

170

171

172

173

174

175

176

177

178

179

180

181

182

183

184

185

186

187

188

189

190

191

192

193

194

195

196

197

198

199

200

facilities, but had no experience with the attention bias test. All sheep were bred, raised and tested on the same farm in Armidale, Australia.

\section{Drug details}

All drugs were administered as a single intramuscular (i.m.) injection into the rump of the animal, 30 min prior to testing in the attention bias test. An anxiety-like state was induced in the Anxious group using the anxiogenic drug m-chlorophenylpiperazine (mCPP; Tocris, Bristol, UK). This drug has previously been shown to significantly impact on animal behavior 30 mins after i.m. administration (Lee et al., 2016; Monk et al., 2018a,b). The mCPP was administered at a dose rate of $1.5 \mathrm{mg} / \mathrm{kg}$. This is a reduced rate compared to previous studies, as recommended by Monk et al. (2018a), due to the observation of abnormal behaviors at the higher dose rate of $2 \mathrm{mg} / \mathrm{kg}$. Prior to treatment, $\mathrm{mCPP}$ was dissolved in BP Water for Injection (Baxter, Old Toongabbie, Australia) at a rate of $60 \mathrm{mg} / \mathrm{ml}$. A calm-like state was induced in the Calm group using the anxiolytic drug diazepam (Troy Laboratories, Sydney, Australia). The diazepam was administered at a dose rate of $0.1 \mathrm{mg} / \mathrm{kg}$ as per previous studies (Lee et al., 2016; Monk et al., 2018b). The drug was administered i.m. rather than intra-venously (i.v.) for consistency across treatment groups. Studies in humans have shown complete bioavailability of diazepam after i.m. injection, with rapid absorption from muscle peaking at around $30 \mathrm{~min}$ (Divoll et al., 1983; Moore et al., 1991). A euphoric-like state was induced in the Happy group using the drug morphine (Hospira, Melbourne, Australia). The morphine was administered at a dose rate of $1 \mathrm{mg} / \mathrm{kg}$ as per previous studies (Verbeek et al., 2012, 2014). Plasma morphine concentration is shown to peak within $20 \mathrm{~min}$ after i.m. administration in humans, with $100 \%$ systemic availability (Stanski, Greenblatt \& Lowenstein, 1978). In sheep, Morphine is shown to have a half-life of approximately $119 \mathrm{~min}$ in blood plasma after i.v. administration (Bengtsson et al., 2009). The Control group were given $1 \mathrm{ml}$ of BP saline i.m. (Baxter, Old Toongabbie, Australia).

\section{Attention bias test}

The current study used the same attention bias test described by Monk et al. (2018a) (Fig 1).

Briefly, the test arena consisted of a concrete yard surrounded by $1.8 \mathrm{~m}$ high opaque walls. There was a small window located on one wall of the arena, which could be completely covered with a retractable opaque cover. Directly opposite the window was an approximately life-size photograph of an unfamiliar female conspecific. Once a sheep entered the arena, an unfamiliar dog was visible to the sheep through the window for $3 \mathrm{~s}$, then the window was covered and the dog was removed. The sheep then remained in the arena for $3 \mathrm{~min}$, while behaviors were recorded using a Sony Handicam video camera (Sony, Australia, model number HDR-XR550) that was positioned above the test arena in an adjacent building. A line of metal panels were positioned inside the arena so that sheep could not move into the corners out of view of the camera (Fig 1). The total accessible area of the arena was $4 \times 4.2 \mathrm{~m}$. 


\section{Behavioral measures in the attention bias test}

202 The behaviors recorded in the attention bias test are summarized in Table 1. Most behaviors were

203

204

205

206

207

208

209

210

211

212

213

214

215

216

217

218

219

220

221

222

223

224

225

226

227

228

229

230

231

232

233

234

235

236

237

238

239

240 collated from video footage using The Observer XT 12.0 (Noldus Information Technology, Wageningen, The Netherlands). Behaviors were continuously recorded for the test duration. During the video analysis the test arena was divided into 9 grid sections (zones) which were overlaid on video footage, to calculate zones crossed, zones entered and zone durations (Table 1). Open- and close-mouthed vocalizations were scored on the day of testing by an experienced hidden observer, who was positioned behind the opaque matting out of view of the sheep. The same observer also scored the dog's behavior on a 3 point scale as: 1 - quietly stood still, 2 lunged or crouched down or 3 - barked or growled at the sheep with any posture. A score of 3 was given on 6 occasions, for 1 animal in the Control group, 2 animals in the Anxious group and 3 animals in the Calm group.

Sheep treated with mCPP were also monitored for abnormal behaviors previously described by Doyle et al. (2015). These included ataxic gait, tail shaking, head shaking, body shaking and head rolling. Tail shaking was observed in 4 sheep during testing. No other abnormal behaviors were observed during testing.

\section{Internal body temperature}

Internal body temperature was recorded using Thermochron iButtons ${ }^{\circledR}$ (Model number DS1922L-F5, accuracy $0.5^{\circ} \mathrm{C}$, resolution $0.063^{\circ} \mathrm{C}$, weight $3.3 \mathrm{~g}$; Embedded Data Systems, Lawrenceburg, USA). The iButtons were attached to blank (progesterone-free) Controlled Internal Drug Release devices (CIDR $\AA$, Zoetis, Melbourne, Australia) using polyolefin heatshrink tubing, as described by Lea et al. (2008). A CIDR was inserted into the vagina of each sheep one day prior to testing using an applicator lubricated with obstetrical lubricant. The iButtons were set to log at an interval of $20 \mathrm{~s}$ beginning $30 \mathrm{~min}$ prior to attention bias testing. Data were extracted using the program eTemperature version 8.32 (OnSolution, Castle Hill, Australia). Data from 4 temperature loggers were missing due to technical faults.

Body temperature data were extracted at times $-30,-20,-10,-1,6,11,15,21$ and 26 min relative to the beginning of attention bias testing. For each time point, the average of 3 consecutive temperature recordings were used. Times -1 and 6 min were identified as the average baseline and peak temperatures before and after attention bias testing across treatment groups.

\section{Statistical Methods}

Data were analyzed using R version 3.5.1 (R Core Team, 2018). P values less than 0.05 were considered significant and $\mathrm{P}<0.1$ were considered a tendency towards significance. All model residuals were checked for normality and homoscedasticity using Shapiro-Wilks test for normality and visual assessment of Q-Q and residuals vs fitted values plots. Treatment group, test order within each test day and dog behavior score were fitted as fixed effects in all linear 
241 models. Test order and dog behavior did not reach significance in any of the models and were 242 subsequently removed using a backward elimination approach, considering both the Akaike and

243 Bayesion information criterion. Cohort (test day) was fitted as a random effect in all mixed

244 effects models. The package nlme was used to fit linear mixed effects models (Pinheiro et al., 245 2016). The package lme 4 was used to fit generalized linear mixed effects models (Bates et al., 246 2015). Post hoc multiple comparisons were conducted using a Tukey method for adjustment of $P$ 247 values. Where significant differences were found between groups, effect sizes were estimated 248 using Pearson's correlation coefficient $r$ (Field et al. 2012). Estimates of effect size were not made for count data.

250

Attention and vigilance data were analyzed using linear mixed effects models. Data for attention

252 to photo wall and vigilance were log transformed to meet normality assumptions. A Kruskal-

253

254

255

256

257

258

259

260

261

262

263

264

265

266

267

268

269

270

271

272

273

274

275

276

277

278

279

Wallis non-parametric ANOVA was also used to confirm the analysis of the vigilance data as the residuals were only marginally improved by transformation. Post hoc multiple comparison tests for the Kruskal-Wallis ANOVA were performed using the package pgirmess (Giraudoux, 2016).

Photo sniff frequency and number of zones entered were analyzed using generalized linear mixed effects models with a Poisson distribution for count data. Sniff environment frequency and zones crossed were analyzed using generalized linear mixed effects models with a negative binomial distribution due to evidence of over-dispersion. Vocalization data were analyzed using a negative binomial hurdle model using the package pscl, to account for the presence of excess zeros in the dataset (Zeileis, Kleiber \& Jackman, 2008). Data for time spent in the zone closest to the photo were analyzed using a linear mixed effects model. The number of animals in each group that entered the zone closest to the dog wall were analyzed using a Fisher's Exact Test. Post hoc multiple comparisons between groups were performed using the package rcompanion (Mangiafico, 2018). Urination data were also analyzed using a Fisher's Exact Test, examining the number of animals in each group that urinated.

All latency data were analyzed with Cox's proportional hazards model using survival analysis (Therneau \& Grambsch, 2000; Therneau, 2015), as described by Monk et al. (2018b). These data included latencies to sniff the photo, sniff the environment and become non-vigilant. Animals that failed to perform each behavior within $180 \mathrm{~s}$ were deemed as censored results. Treatment and test day were fitted as fixed effects in all proportional hazards models.

All body temperature data were analyzed using a linear mixed effects model, fitting treatment, time and a treatment $x$ time interaction as fixed effects. Sheep identity nested within test day was fitted as a random effect to account for the repeated measurements across time points. A subset of the body temperature data was taken from time -1 min onwards to better assess the influence of attention bias testing itself on body temperature responses. Change in body temperature from

Peer) reviewing PDF | (2019:02:34955:2:0:NEW 24 Apr 2019) 
280 time -1 min was analyzed in the same way as the total temperature dataset, fitting a linear mixed 281 effects model to account for repeated measures over time.

282

\section{Results}

\section{Attention and vigilance}

285 Raw attention and vigilance duration data are summarized in Fig 2. Linear mixed effects models 286 showed that duration of attention towards the dog and photo walls did not differ significantly 287 between treatment groups (Table 2 and Fig 3). However, the Anxious and Calm groups tended to 288 spend less time looking towards the dog wall than the Control and Happy groups $(\mathrm{P}<0.1)$.

The linear mixed effects model on vigilance duration data showed no significant differences between treatment groups (Table 2). The Kruskal-Wallis ANOVA on vigilance duration data showed an overall treatment effect; however, post-hoc multiple comparisons showed no differences between the groups (Table 2). Survival analyses showed the Anxious group had a significantly higher latency to become non-vigilant than the other groups, while the Calm and

296

297

298 Happy groups tended to have a higher latency to become non-vigilant than the Control group (Table 3 and Fig 4).

299

300

301

\section{Other behaviors}

The Calm group had the highest frequencies of sniffing the photo and environment while the Anxious group sniffed the photo and environment the least; however, neither group differed

302

303

304

305

306

307

308

309

310

311

312

313

314

315

316

317

318 significantly from the Controls (Table 2). Anxious sheep had a longer latency to sniff the photo and environment than all other treatment groups (Table 3 and Fig 4).

The Happy group crossed and entered more zones than the other groups, while the other groups did not differ (Table 2). The Happy sheep also spent the least amount of time standing near the photo $(r=0.26-0.30)$ and performed more open-mouthed vocalizations than the other groups (Table 2 and Fig 2). More sheep in the Happy group entered the zone closest to the dog wall compared to the Control, Calm and Anxious groups (Table 2). No statistical differences were found between groups for the number of animals that urinated (Table 2).

\section{Body temperature}

The repeated measures analysis on body temperature data from the baseline at $-30 \mathrm{~min}$ showed a significant Treatment $x$ Time interaction $\left(\mathrm{F}_{(24,576)}=4.5, \mathrm{P}<0.001\right)$. Contrasts from the model summary indicated that body temperature did not differ between groups at times $-30 \mathrm{~min}$ or -20 $\min (\mathrm{P}>0.1)$ (Fig 5). At time -10 min, the Anxious group had a significantly higher body temperature than the Calm and Happy groups, but only tended to be higher than the Control group $(t(71)=-1.8, \mathrm{P}=0.069, r=0.21)$. The Anxious group had a higher body temperature than 
319 the other groups at all other time points (Fig 5, $r=0.26-0.34$ ). The Control, Calm and Happy 320 groups did not differ at any time point.

321

322

323

324

325

326

327

328

329

330

331

332

333

334

335

336

337

338

339

340

341

342

343

344

345

346

347

348

349

350

351

352

353

354

355

356

357

358

For change in body temperature after time $-1 \mathrm{~min}$, the Time $\mathrm{x}$ Treatment interaction was not significant $\left(\mathrm{F}_{(15,360)}=0.70, \mathrm{P}=0.78\right)$. The model fitting fixed effects only without the interaction showed no significant effect of treatment on change in body temperature $\left(\mathrm{F}_{(3,72)}=0.24\right.$, $\mathrm{P}=0.865)$.

\section{Discussion}

The pharmacological treatments induced a number of significant effects on behaviors and body temperature; however, in contrast with our hypothesis, the key behaviors of vigilance and looking time did not differ between treatment groups in the current study. There are a number of possible explanations for this, which will be discussed in greater detail throughout the following paragraphs. Firstly, these results could suggest that the modified attention bias test cannot provide a reliable measure of affective states in sheep. Treatment differences between the Control and Anxious groups observed previously during a modified attention bias test were not replicated in the current study (Monk et al., 2018a). This could mean that the results observed in the previous study were an anomaly. It is worth noting, however, that the Anxious group tended to spend less time looking towards the dog wall and displayed a higher level of vigilance than the Control animals, albeit not strongly supported statistically, which is consistent with our expectations and the previous study (Monk et al., 2018a). Further, the Anxious group did have a significantly longer latency to become non-vigilant than the other groups. Finally, the Calm group tended to spend less time looking towards the dog wall than the Control and Happy groups. Thus, we would suggest the current study does not indicate the attention bias test is not useful as a measure of affective states in sheep, but rather that it may not be as sensitive to these changes as previously shown, or that additional factors impacted on animal behavior during this study, as discussed below.

One external factor that may have influenced animal behavior in the current study was the presence of background noise during testing. Throughout both test days, there was unexpected work being conducted in a nearby sheep handling facility. This meant there was some distant background noise consisting of conspecific vocalizations and vehicle movement. At the time of testing, the researchers had not expected this level of noise to impact on the behavior of the sheep being tested. Further, the noise was consistent and repetitive, spanning across the test period so that all treatment groups were exposed to a similar level of noise. However, the noise may have caused the test animals to reach a maximum level of vigilance. The overall time spent vigilant was higher in the current study relative to previous studies (Lee et al., 2016; Monk et al., 2018a,b). Further, there was a high number of censored data points, with 24 of 80 animals showing vigilance behavior for the entire test duration. The prevalence of censored data was 
359

360

361

362

363

364

365

366

367

368

369

370

371

372

373

374

375

376

377

378

379

380

381

382

383

384

385

386

387

388

389

390

391

392

393

394

395

396

397

398

much higher than in the previous study, during which only 4 of 50 animals were vigilant for the entire duration of the test (raw data generated by Monk et al., 2018a). If the duration of vigilance reached a behavioral and temporal maximum within the given test duration, this would have reduced the amount of variation in the data and power of the test to discriminate between treatment groups. Notably, more sheep in the Anxious group were vigilant for the entire test duration. Thus, for vigilance duration, the Anxious group mean was impacted to a greater extent than other groups, and may have disproportionately disguised the extent of heightened vigilance in this group. This is reflected by the survival analysis on latency to become non-vigilant, which accounted for the censoring of vigilance data and showed a significant treatment effect. The background noise may have also impacted on looking time measures, as the noise was coming from the direction of the dog wall. However, the mean times spent looking towards the dog wall for all animals were 59 and $61 \mathrm{~s}$ for the current study and Monk et al. (2018a), respectively, suggesting the influence on direction of attention was minimal. Nevertheless, it cannot be ruled out that the presence of background noise impacted on vigilance and looking behaviors in the test. Consideration of the potential influence of background noise on animal responses will be of particular importance if applying the test in a commercial, on-farm setting, in which affective states are induced by the animals' environments.

An alternative explanation for a lack of response could be that the drugs or doses were inappropriate for modifying affective states or did not induce the expected affective states. During the current study, the Calm animals tended to spend less time looking towards the dog wall as predicted. However differences between the Calm and Control groups were not significant for any observed behavior, contrasting with previous studies using the same dose rate of diazepam (Lee et al., 2016; Monk et al., 2018b). During the original attention bias test method, vigilance and eating behaviors were mutually exclusive. This means that increased time spent eating would have automatically caused a reduction in vigilance behavior. This is important to note as diazepam has been shown to increase appetite in other animal species (Foltin, 2004; Gaskins, Massey \& Ziccardi, 2008). Thus, the decrease in vigilance shown previously may have been due to a drug effect on appetite rather than the influence of a calm state on attention biases in sheep. Another factor worth noting is that the drug had previously been administered intra-venously rather than intra-muscularly. In humans, complete bioavailability of diazepam has been demonstrated after intra-muscular injection, with peak levels occurring around $30 \mathrm{~min}$ (Divoll et al., 1983; Moore et al., 1991). However, no studies in sheep have administered diazepam intra-muscularly at the same dose rate used in the current study. As diazepam or its metabolites were not directly measured in the current study, the efficacy of the drug cannot be confirmed. Further, injection of diazepam did not attenuate the stress-induced hyperthermia caused by attention bias testing. This contrasts with previous studies in cattle (Lee et al., 2017) and rodents and suggests the drug may not have had a strong anxiolytic effect in the current study (Olivier et al., 2003; Bouwknecht, Olivier \& Paylor, 2007). It is also worth noting that a number of studies using diazepam in livestock and humans have 
399 found inconclusive or inconsistent effects (Clarke et al., 2014; Doyle et al., 2015; Lee et al., 400 2017; Mandelli et al., 1978). Further studies including pharmacokinetic assessment are required 401 to validate the use of diazepam as an anxiolytic treatment in sheep and other livestock species.

402

403

404

405

406

407

408

409

410

411

412

413

414

415

416

417

418

419

420

421

422

423

424

425

426

427

428

429

430

431

432

433

434

435

436

437

438

Evidence for the use of morphine to manipulate affective states in sheep is currently limited, with few studies using the drug with this intended effect. In the current study, morphine had no effect on key measures of attention bias, but did seem to increase arousal as predicted. Happy sheep crossed and entered more zones and were more vocal than Control animals, which is consistent with previous studies using the same dose of morphine (Verbeek et al., 2012, 2014). While it appears morphine has an effect on arousal, its influence on the valence component of affect is less clear. Happy sheep did not show reduced vigilance or increased exploratory behavior during the test, previously thought to indicate a less-negative state (Monk et al., 2018a). Instead, increased activity during isolation can be considered a fearful response for sheep (Romeyer \& Bouissou, 1992; Forkman et al., 2007). Previously, Verbeek et al. (2012) demonstrated changes in ear posture after morphine treatment which were suggestive of decreased fearfulness (Reefmann et al., 2009). Verbeek et al. (2014) demonstrated an enhanced optimistic judgement bias after consumption of a food reward, suggestive of a more positive mood after treatment (Paul, Harding \& Mendl, 2005). Therefore, it is possible that increased activity during the current study did not reflect increased fearfulness, but rather supports the suggestion by Verbeek et al. (2012) that the opioid system may be involved in the arousal component of affective state. The potential influence of morphine on the valence component of affect in sheep remains inconclusive. Further studies validating the use of this drug, or exploring alternative methods for inducing positive affective states, would be useful for understanding affective states and attention biases in sheep.

The drug mCPP has been used previously to induce anxious states in sheep, including studies of attention bias. However the current study used a reduced rate of $1.5 \mathrm{mg} / \mathrm{kg}$ compared to the rate of $2 \mathrm{mg} / \mathrm{kg}$ used previously (Lee et al., 2016; Monk et al., 2018a,b). It could therefore be possible the reduced dose-rate was insufficient to cause an equivalent anxiety-like response. However, the mCPP treated sheep showed a significant increase in body temperature after injection compared to the other treatment groups. Although mCPP did not potentiate the stress-induced hyperthermia caused by attention bias testing, the drug itself caused a significant increase in body temperature compared to all other treatment groups, which is consistent with an anxiety-like state and previous studies (Sherwood, Klandorf \& Yancey, 2005; Bouwknecht, Olivier \& Paylor, 2007; Pedernera-Romano et al., 2010; Lee et al., 2017; Monk et al., 2018a). The Anxious group also showed behavioral signs of increased anxiety during testing, displaying a higher latency to become non-vigilant and a higher latency to sniff the photo and environment compared to Control animals (Romeyer \& Bouissou, 1992; Beausoleil, Stafford \& Mellor, 2005; Beausoleil et al., 2012). Doyle et al. (2015) had also found that a lower dose of $1 \mathrm{mg} / \mathrm{kg}$ induced anxiety-like behaviors in young sheep during runway, startle and isolation tests. Overall, it appears that the 
439 dose of $1.5 \mathrm{mg} / \mathrm{kg}$ did cause an anxious-like response prior to and during testing. It is

440 recommended that further studies continue to use the reduced dose rate of $1.5 \mathrm{mg} / \mathrm{kg}$ in adult

441 sheep to lessen the presence of unwanted side-effects. We suggest the key behaviors of vigilance

442 duration and looking time did not differ between the Anxious and Control groups due to the

443

444

445

446

447

448

449

450

451

452

453

454

455

456

457

458

459

460

461

462

463

464

465

466

467

468

469

470

471

472

473

474

475

476

477

478 censoring of vigilance data or the influence of other confounding factors.

Additional factors such as animal age, sex, parity and experience with dogs may have also influenced animal responses in the test. Previously, attention biases have been demonstrated in both male and female sheep ranging from 5 months old to 2 years old, while the current study assessed 7-year-old ewes. In humans, age has been found to alter the direction of attention biases (Isaacowitz et al., 2008). In sheep, previous experience with humans, age and parity have been shown to alter fearfulness (Viérin \& Bouissou, 2002; Dodd et al., 2012). Notably, routine handling procedures on-farm, such as shearing and mustering to handling facilities with the use of dogs, are associated with indicators of behavioral and physiological stress in sheep and are shown to influence animal behavior during future procedures (Dwyer, 2009). Given that these older animals predominantly had negative experiences with humans and dogs throughout their lives, they may have developed a negative association with handling, which may have influenced their responses during testing. Additionally, animal age may have impacted the effect and metabolism of the drugs used in the study. For example, in humans, age is shown to impact the volume distribution and clearance rate of diazepam, as well as the metabolite concentration and peak time (Klotz et al., 1975; Divoll et al., 1983). In rats, morphine is shown to have a variable effect on behavior and nociception in 8-week-old versus 24-week-old animals (Paul, Gueven \& Dietis, 2018). Understanding the potential influence of these factors on animal responses will allow for a clearer interpretation of behavior during attention bias studies.

Another factor that should be noted is the choice of positive and negative stimuli in the current test methodology. The negative stimulus was a live dog, which was presented for only $3 \mathrm{~s}$ of the test. The positive stimulus was a photograph of a conspecific, which was present for the entire test duration. As such, the positive and negative stimuli used in the current study were not balanced in intensity and presentation time. Within the context of the current study, attention biases are being assessed within treatment groups relative to other treatment groups. This means the key question is not whether an individual pays more attention towards the dog window relative to the photograph, but rather whether a treatment group pays more attention towards the dog window relative to the other treatment groups being tested. Consequently, discrepancies between the positive and negative stimulus intensities and stimulus presentation times should not have impacted on our results, as these factors were consistent across all tested animals. However, it cannot be ruled out that the drugs may have impacted an animal's perception of the stimuli and therefore their responses. For example, if the Anxious sheep perceived the photograph as a conspecific to a greater degree than the other groups, this could explain an additional attraction to the stimulus. Further studies should be conducted to better understand how animals perceive 
479

480

481

482

483

484

485

486

487

488

489

490

492

493

494

495

496

497

498

499

500

501

502

503

504

505

506

507

508

509

510

511

512

513

514

515

516

\section{Conclusions} al., 2015).
491

and respond to the stimuli presented during attention bias tests. Such studies should not only consider the salience of the stimuli, but should also consider the type of stimuli used with regards to the primary sensory systems of the animals being tested (Raoult \& Gygax, 2018, Winters et

Additionally, it is important to consider that the stimuli used in the current study may not be generalizable to other studies and populations. We used a single dog for all tests to control for the potential effects of dog disposition or temperament on sheep responses. However, different dogs may evoke different behavioral responses in sheep during future studies. We note here that the photograph used in the current study has been made publicly available by Monk et al. (2018a) for use in further research; however, this photo may be less suitable for studies in different sheep breeds. Sheep have been shown to discriminate valenced photographs of conspecifics, and to generalize this discrimination of valenced faces to photos of different individuals (Bellegarde et al., 2017). As such, we do not expect that minor changes to conspecific photographs would have a great impact on animal responses. Nevertheless, future studies aiming to better understand how animals perceive and appraise different types of stimuli should take this into consideration.

The current study highlights a number of key areas for further research. Studies understanding the potential influence of factors such as age, experience and background noise on animal responses may allow the method to be adjusted or interpreted accordingly for different populations of animals or for different testing environments. It is suggested the test might be better suited to younger groups of animals that have had less experience with dogs and with routine handling practices that could influence their responses in the test. Inclusion of a habituation period could reduce the overall vigilance levels by reducing the fear-eliciting elements of the test itself, allowing clearer separation of vigilance between animals (Erhard, Elston \& Davidson, 2006). However, this would limit the test's application to a larger population of animals in an on-farm setting. Understanding the influence of background noise will be of particular importance if applying the test in a commercial, on-farm setting. It would be useful to examine the impact of other environmental and pharmacological manipulations on responses in the modified attention bias test. Studies examining environmental manipulations should utilize experiences and environments that are relevant to livestock production systems to facilitate the future application of the test in an on-farm setting. Studies examining pharmacological models should aim to better understand the way in which the models impact on the valence of affective state. This will best be done by utilizing a variety of methods, such as place preference tests and operant conditioning tasks. Finally, further studies should be conducted to examine the influence of different types of positive and negative stimuli on animal responses.

518 
519 It remains unclear whether the attention bias test can be used to detect positive affective states in 520 sheep. Further, the current study was not able to replicate previous findings that negative

521 affective states influenced responses in the modified attention bias test. It is suggested the current 522 study should be repeated on a population of younger animals, making sure to reduce or eliminate 523 background noise during testing, which may have confounded results. Further studies should be 524 conducted to confirm the effects of the given pharmacological agents and to ensure the doses and 525 administration routes are appropriate to induce specific affective states. It may be useful to 526 explore alternative pharmacological agents for inducing affective states in sheep, and to examine 527 the impact of environmental manipulations on attention biases.

528

529

530

531

532

533

534

535

536

537

538

539

540

541

542

543

544

545

546

547

548

549

550

551

552

553

554

555

556

557

558

559

560

561

\section{Acknowledgements}

The authors would like to thank the staff and students at CSIRO for their assistance during the experiments: Jim Lea, Tim Dyall, Troy Kalinowski and Koli the dog. We would like to thank Alison Small for her advice and assistance with the drug treatment protocol. The first author would like to thank the Sheep CRC for supporting her postgraduate studies.

\section{References}

Bar-Haim Y, Lamy D, Pergamin L, Bakermans-Kranenburg MJ, van IJzendoorn MH. 2007. Threat-related attentional bias in anxious and nonanxious individuals: a meta-analytic study. Psychological Bulletin 133:1-24. DOI: 10.1037/0033-2909.133.1.1.

Bates D, Mächler M, Bolker B, Walker S. 2015. Fitting Linear Mixed-Effects Models Using lme4. Journal of Statistical Software 67:1-48. DOI: 10.18637/jss.v067.i01.

Beausoleil NJ, Blache D, Stafford KJ, Mellor DJ, Noble ADL. 2012. Selection for temperament in sheep: Domain-general and context-specific traits. Applied Animal Behaviour Science 139:74-85. DOI: 10.1016/j.applanim.2012.02.020.

Beausoleil NJ, Stafford KJ, Mellor DJ. 2005. Sheep show more aversion to a dog than to a human in an arena test. Applied Animal Behaviour Science 91:219-232. DOI: 10.1016/j.applanim.2004.10.008.

Bellegarde LGA, Erhard HW, Weiss A, Boissy A, Haskell MJ. 2017. Valence of Facial Cues Influences Sheep Learning in a Visual Discrimination Task. Frontiers in Veterinary Science 4. DOI: $10.3389 /$ fvets.2017.00188.

Bengtsson J, Ederoth P, Ley D, Hansson S, Amer-Wåhlin I, Hellström-Westas L, Marsál K, Nordström C-H, Hammarlund-Udenaes M. 2009. The influence of age on the distribution of morphine and morphine-3-glucuronide across the blood-brain barrier in sheep. British Journal of Pharmacology 157:1085-1096. DOI: 10.1111/j.1476-5381.2009.00242.x.

Bouwknecht JA, Olivier B, Paylor RE. 2007. The stress-induced hyperthermia paradigm as a physiological animal model for anxiety: A review of pharmacological and genetic studies in the mouse. Neuroscience \& Biobehavioral Reviews 31:41-59. DOI: 10.1016/j.neubiorev.2006.02.002.

Bradley BP, Mogg K, Lee SC. 1997. Attentional biases for negative information in induced and naturally occurring dysphoria. Behaviour Research and Therapy 35:911-927. DOI: 10.1016/S0005-7967(97)00053-3. 
562 Bradley BP, Mogg K, Millar N, White J. 1995. Selective processing of negative information:

563 effects of clinical anxiety, concurrent depression, and awareness. Journal of abnormal

564 psychology 104:532-536. DOI: 10.1037//0021-843x.104.3.532.

565 Caudek C, Ceccarini F, Sica C. 2017. Facial expression movement enhances the measurement of

566 temporal dynamics of attentional bias in the dot-probe task. Behaviour Research and

567 Therapy 95:58-70. DOI: 10.1016/j.brat.2017.05.003.

568 Destrez A, Deiss V, Belzung C, Lee C, Boissy A. 2012. Does reduction of fearfulness tend to

569

570

571

572

573

574

575

576

577

578

579

580

581

582

583

584

585

586

587

588

589

590

591

592

593

594

595

596

597

598

599

600

601

602

603

604

605

606

607 reduce pessimistic-like judgment in lambs? Applied Animal Behaviour Science 139:233241. DOI: 10.1016/j.applanim.2012.04.006.

Divoll M, Greenblatt DJ, Ochs HR, Shader RI. 1983. Absolute bioavailability of oral and intramuscular diazepam: effects of age and sex. Anesthesia and analgesia 62:1-8.

Dodd CL, Pitchford WS, Hocking Edwards JE, Hazel SJ. 2012. Measures of behavioural reactivity and their relationships with production traits in sheep: A review. Applied Animal Behaviour Science 140:1-15. DOI: 10.1016/j.applanim.2012.03.018.

Doyle RE, Lee C, McGill DM, Mendl M. 2015. Evaluating pharmacological models of high and low anxiety in sheep. PeerJ 3:e1510. DOI: 10.7717/peerj.1510.

Drake KA. 2006. The neurophysiological regulation of temperament in sheep. [doctoral thesis]. University of New England, Australia. University of New England, Armidale, NSW.

Dwyer CM. 2009. Welfare of sheep: Providing for welfare in an extensive environment. Small Ruminant Research 86:14-21. DOI: 10.1016/j.smallrumres.2009.09.010.

Erhard HW, Elston DA, Davidson GC. 2006. Habituation and extinction in an approachavoidance test: An example with sheep. Applied Animal Behaviour Science 99:132-144. DOI: 10.1016/j.applanim.2005.10.008.

Field AP, Miles J, Field Z. 2012. Discovering statistics using R. London: SAGE.

Foltin RW. 2004. Effects of amphetamine, dexfenfluramine, diazepam, and dietary manipulations on responding reinforced by stimuli paired with food in nonhuman primates. Pharmacology Biochemistry and Behavior 77:471-479. DOI: 10.1016/j.pbb.2003.12.013.

Forkman B, Boissy A, Meunier-Salaün MC, Canali E, Jones RB. 2007. A critical review of fear tests used on cattle, pigs, sheep, poultry and horses. Physiology and Behavior 92:340-374. DOI: 10.1016/j.physbeh.2007.03.016.

Gaskins LA, Massey JG, Ziccardi MH. 2008. Effect of oral diazepam on feeding behavior and activity of Hawai'i 'amakihi (Hemignathus virens). Applied Animal Behaviour Science 112:384-394. DOI: 10.1016/j.applanim.2007.07.008.

Giraudoux P. 2016. pgirmess: Data Analysis in Ecology. R package version 1.6.4.

Grafton B, Ang C, MacLeod C. 2012. Always Look on the Bright Side of Life: The Attentional Basis of Positive Affectivity. European Journal of Personality 26:133-144. DOI: 10.1002/per.1842.

Isaacowitz DM, Toner K, Goren D, Wilson HR. 2008. Looking While Unhappy. Psychological Science 19:848-853. DOI: 10.1111/j.1467-9280.2008.02167.x.

Klotz U, Avant GR, Hoyumpa A, Schenker S, Wilkinson GR. 1975. The effects of age and liver disease on the disposition and elimination of diazepam in adult man. Journal of Clinical Investigation 55:347-359. DOI: 10.1172/JCI107938.

Lea JM, Niemeyer DDO, Reed MT, Fisher AD, Ferguson DM. 2008. Development and validation of a simple technique for logging body temperature in free-ranging cattle. Australian Journal of Experimental Agriculture 48:741. DOI: 10.1071/EA07422.

Lee C, Cafe LM, Robinson SL, Doyle RE, Lea JM, Small AH, Colditz IG. 2017. Anxiety

PeerJ reviewing PDF | (2019:02:34955:2:0:NEW 24 Apr 2019) 
608

609

610

611

612

613

614

615

616

617

618

619

620

621

622

623

624

625

626

627

628

629

630

631

632

633

634

635

636

637

638

639

640

641

642

643

644

645

646

647

648

649

650

651

652

653

influences attention bias but not flight speed and crush score in beef cattle. Applied Animal Behaviour Science:0-1. DOI: 10.1016/j.applanim.2017.11.003.

Lee C, Verbeek E, Doyle R, Bateson M. 2016. Attention bias to threat indicates anxiety differences in sheep. Biology Letters 12:20150977. DOI: 10.1098/rsbl.2015.0977.

Mangiafico S. 2018. rcompanion: Functions to Support Extension Education Program Evaluation. R package version 2.0.3.

Mendl M, Burman OHP, Parker RMA, Paul ES. 2009. Cognitive bias as an indicator of animal emotion and welfare: Emerging evidence and underlying mechanisms. Applied Animal Behaviour Science 118:161-181. DOI: 10.1016/j.applanim.2009.02.023.

Monk J, Belson S, Colditz I, Lee C. 2018a. Attention bias test differentiates anxiety and depression in sheep. Frontiers in Behavioral Neuroscience 12:1-14. DOI: 10.3389/fnbeh.2018.00246.

Monk JE, Doyle RE, Colditz IG, Belson S, Cronin GM, Lee C. 2018b. Towards a more practical attention bias test to assess affective state in sheep. PLOS ONE 13:e0190404. DOI: 10.1371/journal.pone.0190404.

Moore DH, Smallridge RC, Von Bredow JD, Lukey BJ. 1991. The pharmacokinetics of atropine and diazepam in sheep: Intramuscular co-administration. Biopharmaceutics \& Drug Disposition 12:525-536. DOI: 10.1002/bdd.2510120706.

Olivier B, Zethof T, Pattij T, van Boogaert M, van Oorschot R, Leahy C, Oosting R, Bouwknecht A, Veening J, van der Gugten J, Groenink L. 2003. Stress-induced hyperthermia and anxiety: pharmacological validation. European Journal of Pharmacology 463:117-132. DOI: 10.1016/S0014-2999(03)01326-8.

Paul AK, Gueven N, Dietis N. 2018. Age-dependent antinociception and behavioral inhibition by morphine. Pharmacology Biochemistry and Behavior 168:8-16. DOI: 10.1016/j.pbb.2018.03.003.

Paul ES, Harding EJ, Mendl M. 2005. Measuring emotional processes in animals: The utility of a cognitive approach. Neuroscience and Biobehavioral Reviews 29:469-491. DOI: 10.1016/j.neubiorev.2005.01.002.

Pedernera-Romano C, Ruiz de la Torre JL, Badiella L, Manteca X. 2010. Effect of perphenazine enanthate on open-field test behaviour and stress-induced hyperthermia in domestic sheep. Pharmacology Biochemistry and Behavior 94:329-332. DOI: 10.1016/j.pbb.2009.09.013.

Pinheiro J, Bates D, DebRoy S, Sarkar D, R Core Team. 2016. nlme: Linear and Nonlinear Mixed Effects Models.

R Core Team. 2018. R: a language and environment for statistical computing. R Foundation for Statistical Computing, Vienna, Austria. URL http:/www.R-project.org/.

Raoult C, Gygax L. 2018. Valence and Intensity of Video Stimuli of Dogs and Conspecifics in Sheep: Approach-Avoidance, Operant Response, and Attention. Animals 8:121. DOI: 10.3390/ani8070121.

Reefmann N, Bütikofer Kaszàs F, Wechsler B, Gygax L. 2009. Ear and tail postures as indicators of emotional valence in sheep. Applied Animal Behaviour Science 118:199-207. DOI: 10.1016/j.applanim.2009.02.013.

Riley JL, Hastie BA, Glover TL, Fillingim RB, Staud R, Campbell CM. 2010. CognitiveAffective and Somatic Side Effects of Morphine and Pentazocine: Side-Effect Profiles in Healthy Adults. Pain Medicine 11:195-206. DOI: 10.1111/j.1526-4637.2009.00680.x.

Romeyer A, Bouissou M-F. 1992. Assessment of fear reactions in domestic sheep, and influence of breed and rearing conditions. Applied Animal Behaviour Science 34:93-119. DOI: 
654

655

656

657

658

659

660

661

662

663

664

665

666

667

668

669

670

671

672

673

674

675

676

677

678

679

680

681

682

683

684

$$
\text { 10.1016/S0168-1591(05)80060-7. }
$$

Sanchez A, Vazquez C. 2014. Looking at the eyes of happiness: Positive emotions mediate the influence of life satisfaction on attention to happy faces. The Journal of Positive Psychology 9:435-448. DOI: 10.1080/17439760.2014.910827.

Sherwood L, Klandorf H, Yancey PH. 2005. Animal physiology: from genes to organisms. Australia: Thomson/Brooks/Cole.

Stanski DR, Greenblatt DJ, Lowenstein E. 1978. Kinetics of intravenous and intramuscular morphine. Clinical Pharmacology \& Therapeutics 24:52-59. DOI: 10.1002/cpt197824152.

Tamir M, Robinson MD. 2007. The Happy Spotlight: Positive Mood and Selective Attention to Rewarding Information. Personality and Social Psychology Bulletin 33:1124-1136. DOI: $10.1177 / 0146167207301030$.

Therneau T. 2015. A Package for Survival Analysis in S. version 2.38.

Therneau TM, Grambsch PM. 2000. Modeling Survival Data: Extending the Cox Model. New York, NY: Springer New York. DOI: 10.1007/978-1-4757-3294-8.

Verbeek E, Ferguson D, Quinquet de Monjour P, Lee C. 2012. Opioid control of behaviour in sheep: Effects of morphine and naloxone on food intake, activity and the affective state. Applied Animal Behaviour Science 142:18-29. DOI: 10.1016/j.applanim.2012.09.001.

Verbeek E, Ferguson D, Quinquet de Monjour P, Lee C. 2014. Generating positive affective states in sheep: The influence of food rewards and opioid administration. Applied Animal Behaviour Science 154:39-47. DOI: 10.1016/j.applanim.2014.02.011.

de Vere AJ, Kuczaj SA. 2016. Where are we in the study of animal emotions? Wiley Interdisciplinary Reviews: Cognitive Science 7:354-362. DOI: 10.1002/wcs.1399.

Viérin M, Bouissou M-F. 2002. Influence of maternal experience on fear reactions in ewes. Applied Animal Behaviour Science 75:307-315. DOI: 10.1016/S0168-1591(01)00201-5.

Winters S, Dubuc C, Higham JP. 2015. Perspectives: The Looking Time Experimental Paradigm in Studies of Animal Visual Perception and Cognition. Ethology 121:625-640. DOI: 10.1111/eth.12378.

Zeileis A, Kleiber C, Jackman S. 2008. Regression Models for Count Data in R. Journal of Statistical Software 27:1-25. DOI: 10.18637/jss.v027.i08. 


\section{Figure 1}

Photograph of the attention bias test immediately after the test sheep entered the arena.

The dog was visible for $3 \mathrm{~s}$, then a retractable opaque cover was lowered over the window and the dog was removed. Sheep remained in the test for 3 mins. The "\#" symbol indicates the entrance of the arena, a camera was positioned above the arena to the right of the photograph (not visible in photograph). For a schematic diagram of the arena, see Monk et al. (2018a) . Photo credit: Jessica Monk.

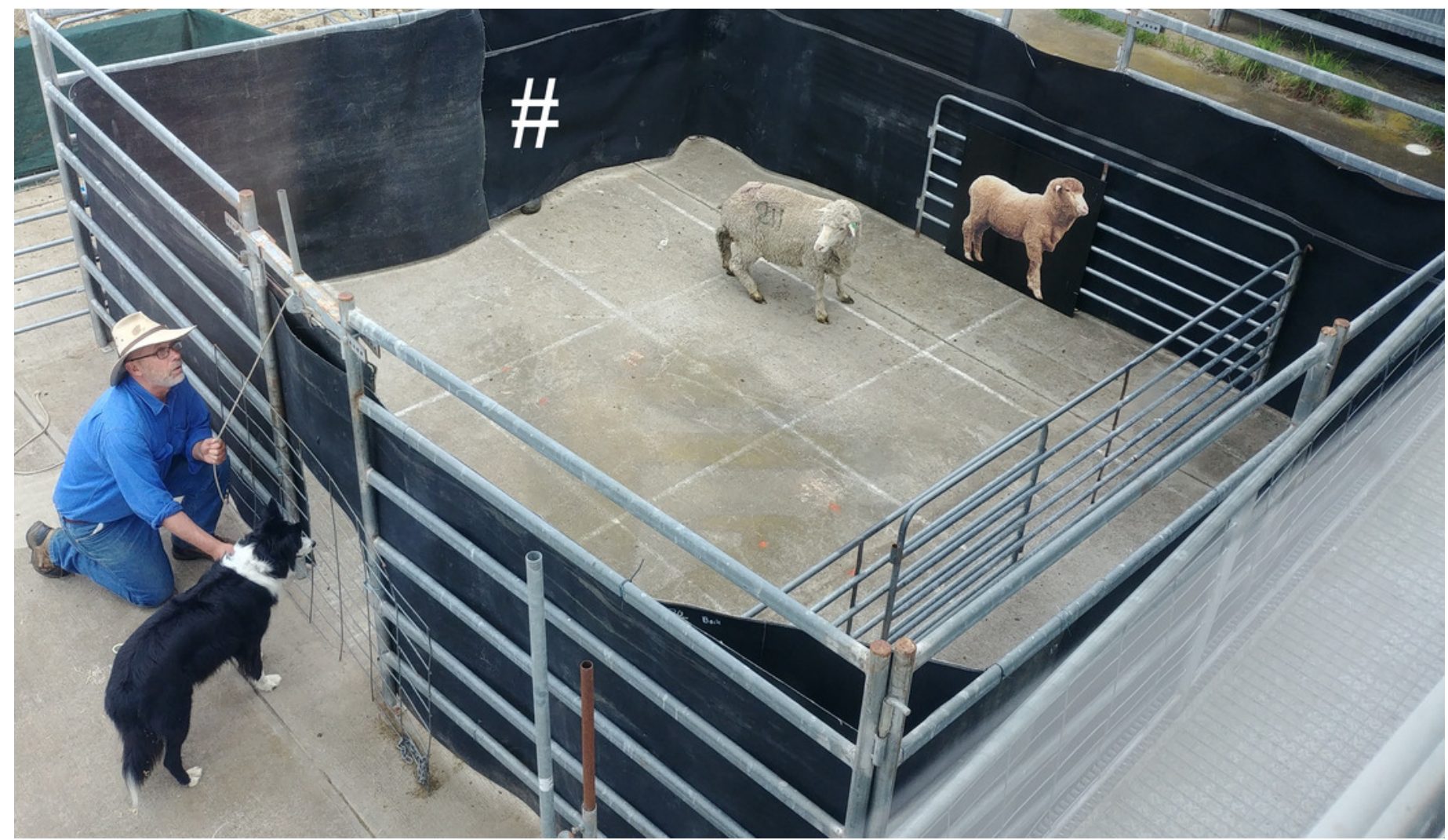




\section{Figure 2}

Boxplots displaying the distribution of observed duration data.

Boxplots show the median durations, the interquartile range (IQR) and the range of data within $1.5 \times$ the IQR for duration of attention to the dog wall (A), attention to the photo wall (B), vigilance (C) and time spent standing in the zone closest to the photo (D). The dots represent raw duration data for each individual sheep within the treatment groups. We note that the plot axes are scaled differently to more clearly display the data within each observed variable. 
A

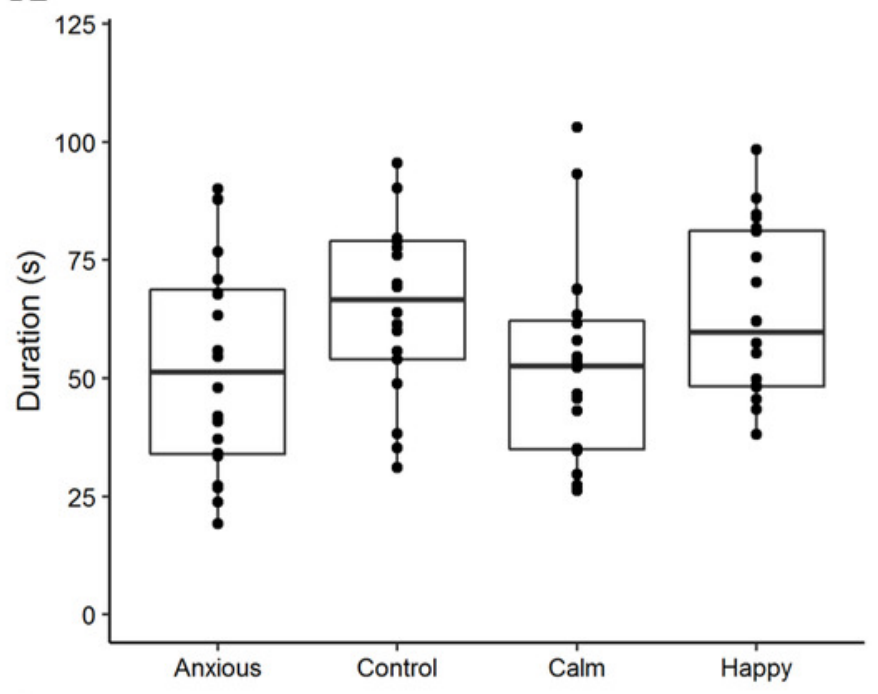

C

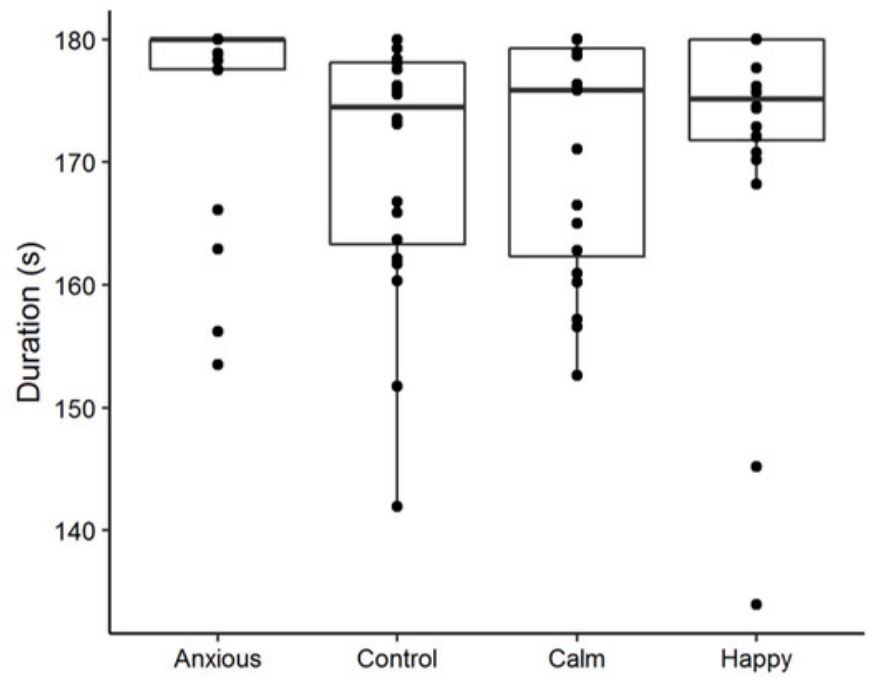

B

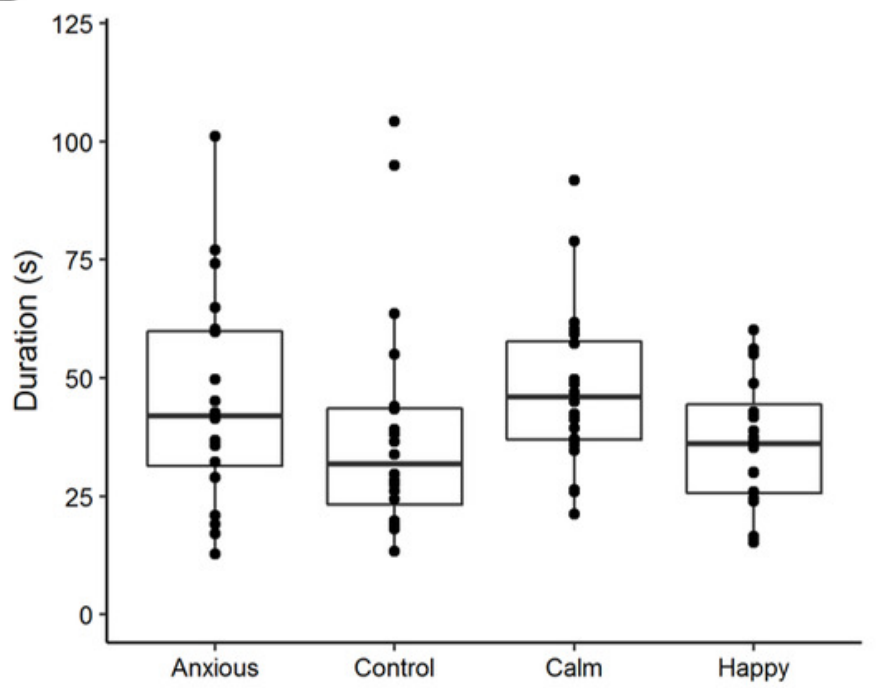

D

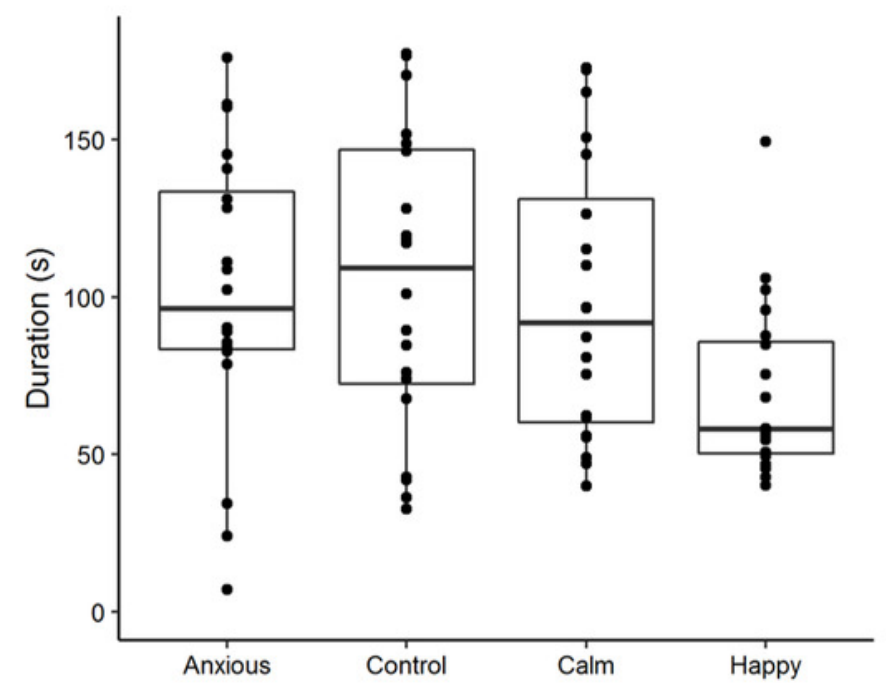




\section{Figure 3}

Mean \pm s.e.m. time spent looking towards the dog wall and the photo wall for each treatment group during attention bias testing.

The times spent looking towards the dog and photo walls were analysed using linear mixed effects models, fitting treatment as a fixed effect and test day as a random effect.

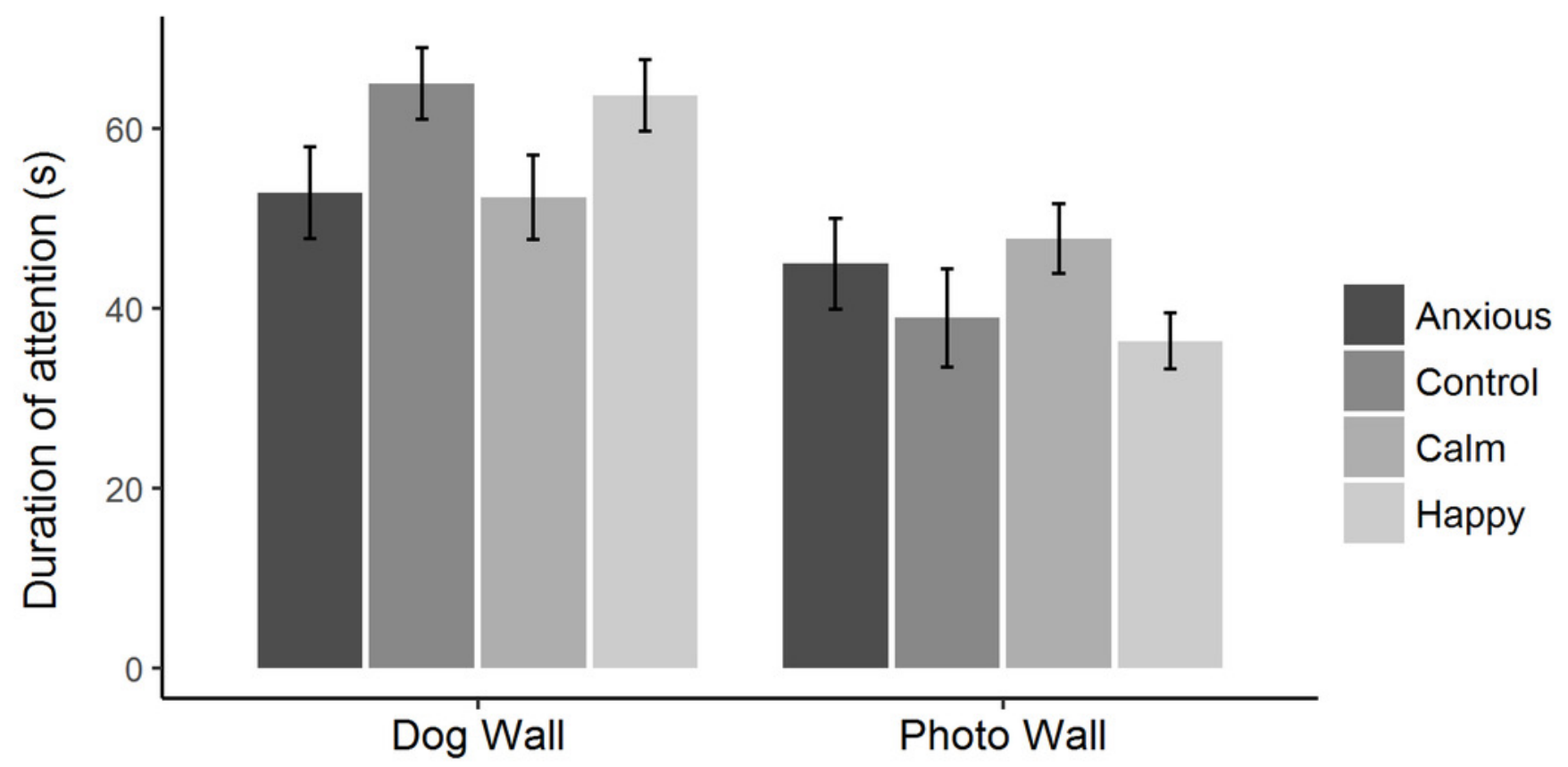


Figure 4

Kaplan-Meier curves for latency to sniff the photo (A), sniff the environment (B) and become non-vigilant (C).

Each time an animal exhibited the given behavior, the probability on the $Y$ axis drops. 
Treatment - - Anxious - Control - - Calm - - Happy

A

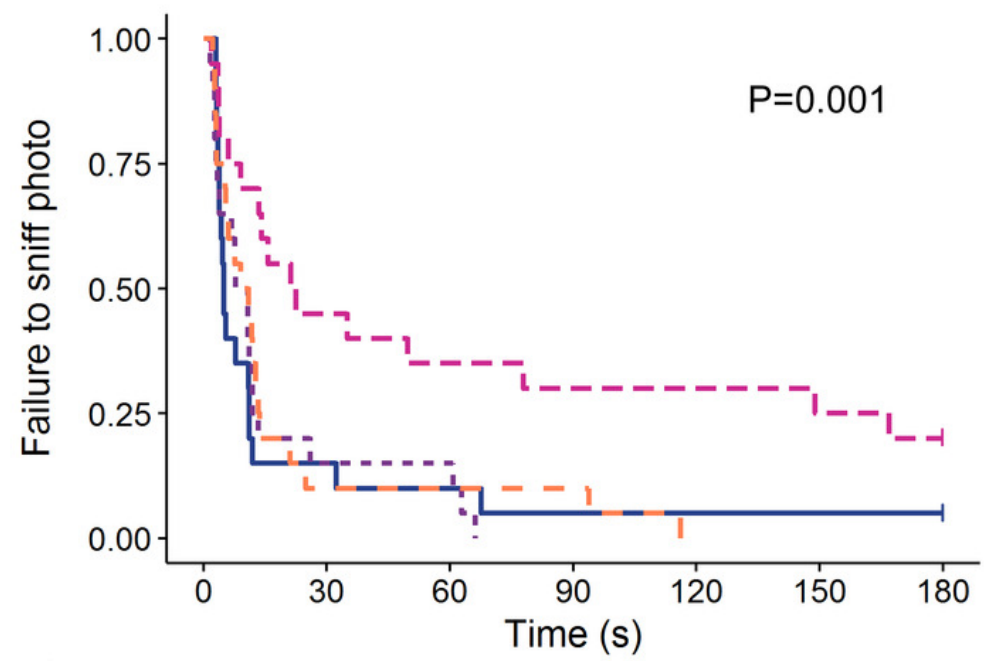

B

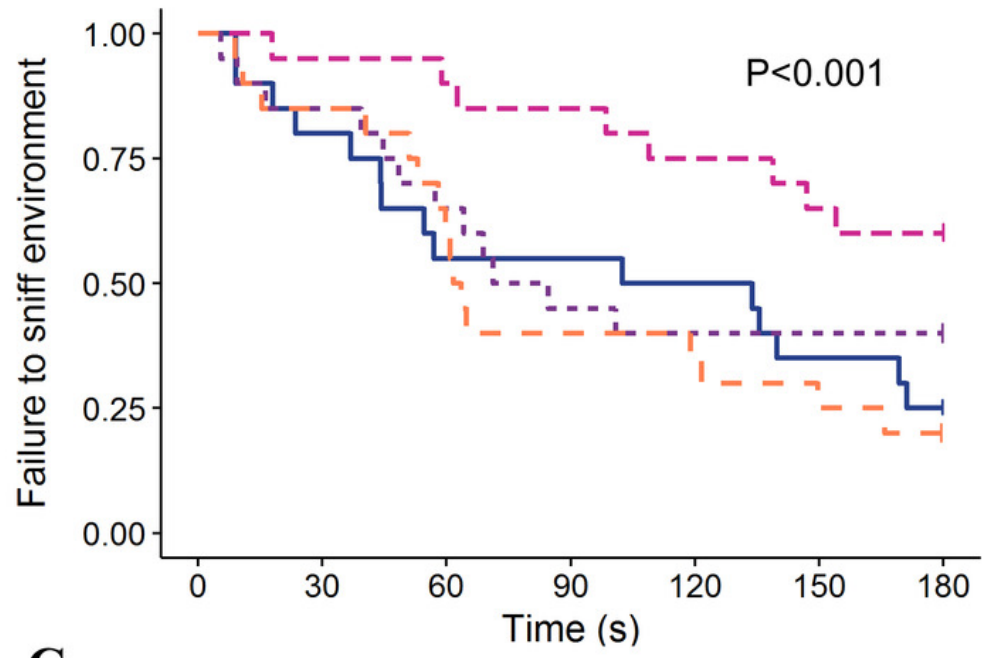

C

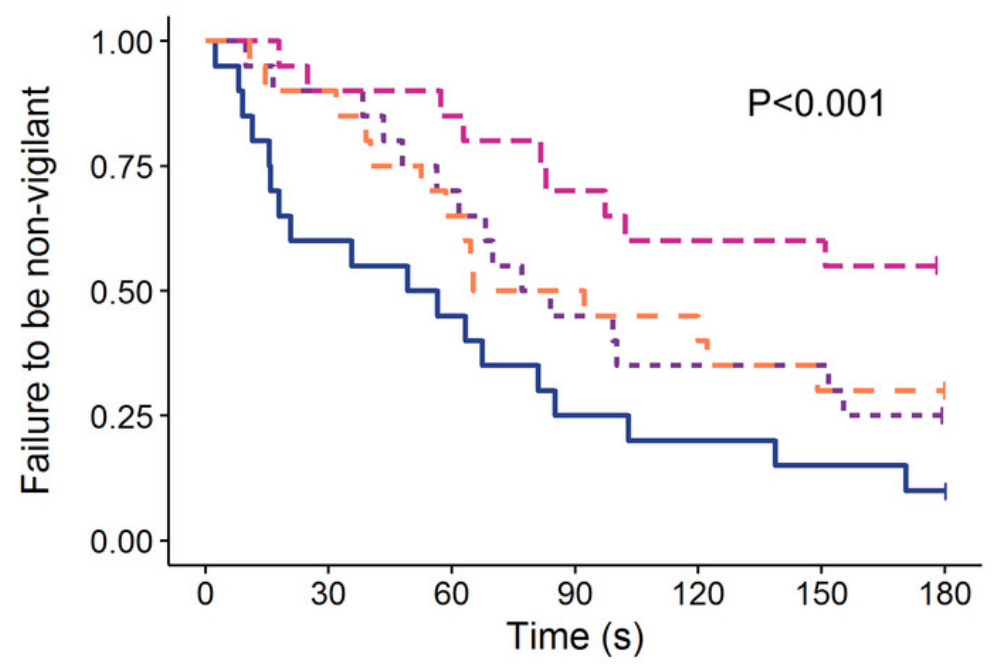


Figure 5

Mean \pm s.e.m. body temperatures for the Anxious (0), Control ( $\mathbf{\square})$, Happy (x) and Calm (A) groups.

All injections were administered at time -30. The grey bar denotes the time of attention bias testing. The letters $(a, b)$ indicate significant differences between groups at time -10 . The ' $*$ ' symbol denotes a significant difference between the Anxious group mean and all other groups as determined using a repeated measures linear mixed model.

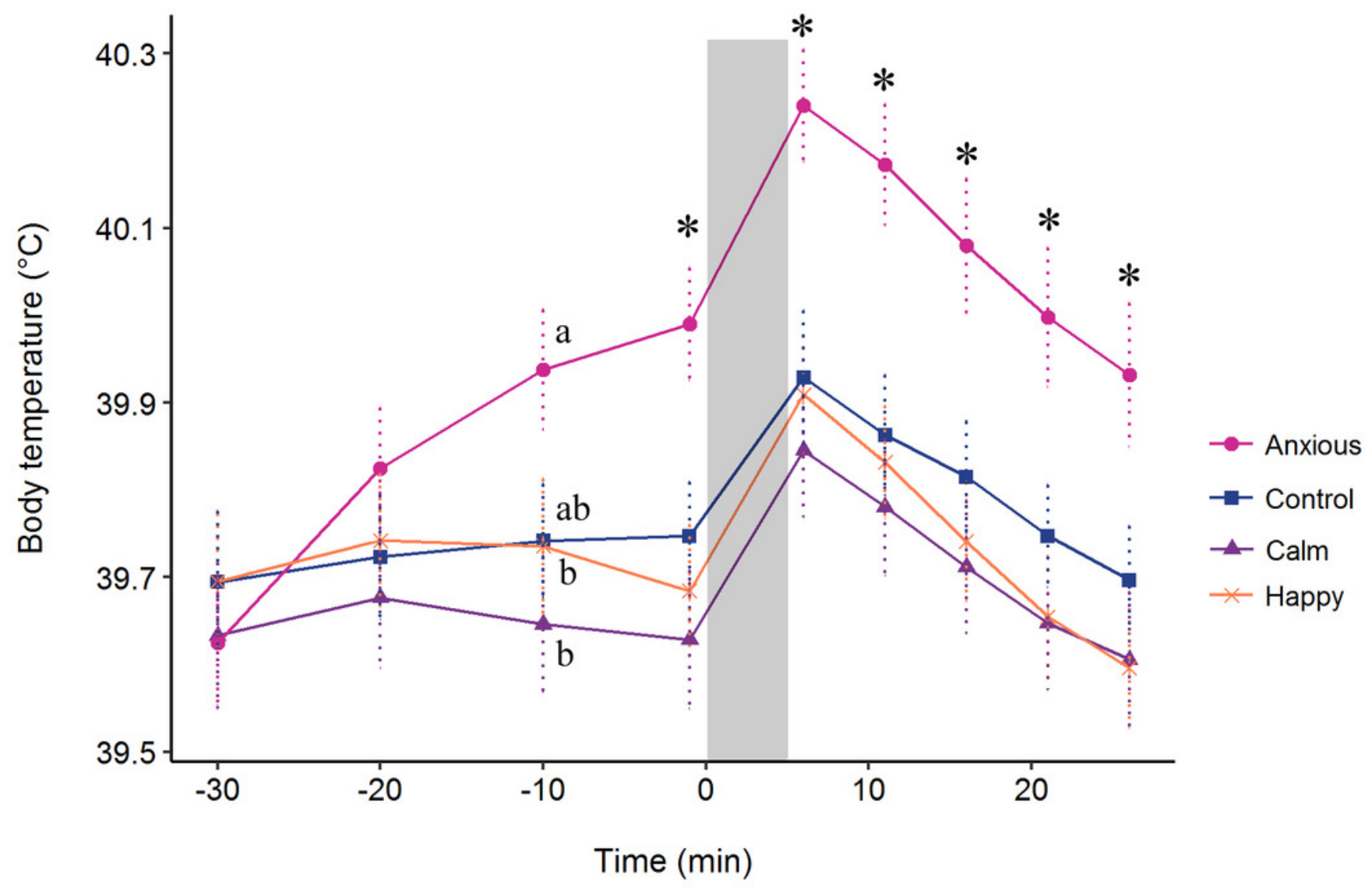




\section{Table 1 (on next page)}

Ethogram of behaviors recorded during the attention bias test (Monk et al., 2018a). 


\begin{tabular}{|l|l|}
\hline Behavior & Definition \\
\hline Attention & $\begin{array}{l}\text { The direction in which the sheep is looking with binocular vision } \\
\text { (Lee et al., 2016; Piggins and Phillips, 1996). The test arena was } \\
\text { divided into 4 areas of attention: dog wall, photo wall, door wall and } \\
\text { back wall. Total duration of attention was recorded for the dog and } \\
\text { photo walls. Duration looking at the other walls were not analyzed as } \\
\text { these areas were not central to our hypotheses. }\end{array}$ \\
\hline Vigilance & $\begin{array}{l}\text { Time spent with the head at or above shoulder height (Frid, 1997; Lee } \\
\text { et al., 2016). Latency to become non-vigilant was also calculated. }\end{array}$ \\
\hline Sniff photo & Number of times and latency to sniff the photo \\
\hline $\begin{array}{l}\text { Sniff } \\
\text { environment }\end{array}$ & $\begin{array}{l}\text { Number of times and latency to sniff the floor or walls of the test } \\
\text { arena }\end{array}$ \\
\hline Vocalizations & $\begin{array}{l}\text { Number of open mouthed bleats and close mouthed bleats were } \\
\text { recorded separately }\end{array}$ \\
\hline Zones crossed & $\begin{array}{l}\text { Number of zones crossed with both front feet placed into the new } \\
\text { zone, or one front foot in the zone and the other on the line }\end{array}$ \\
\hline Zones entered & Number of zones entered (1 to 9) \\
\hline Zone duration & $\begin{array}{l}\text { Total time spent in each of the 9 zones. Data for time spent in the } \\
\text { zone closest to the photo were used for further analysis, as well as } \\
\text { number of entries into the zone closest to the dog window. }\end{array}$ \\
\hline Urinations & Number of urinations \\
\hline
\end{tabular}




\section{Table 2 (on next page)}

Mean \pm s.e.m. behavioral responses of sheep in each treatment group during the attention bias test. 


\begin{tabular}{|c|c|c|c|c|c|c|c|}
\hline Behavioral measure & Anxious & Control & Calm & Happy & Test method & Test value (df) & P value \\
\hline Attention to dog wall (s) & $53.3 \pm 6.7$ & $64.9 \pm 6.7$ & $52.3 \pm 6.7$ & $63.6 \pm 6.7$ & LME & $\mathrm{F}_{(3,76)}=2.4$ & 0.075 \\
\hline Attention to photo wall (s) ${ }^{1}$ & $3.7 \pm 0.2(38.9)$ & $3.5 \pm 0.2(33.4)$ & $3.8 \pm 0.2(44.8)$ & $3.5 \pm 0.2(33.6)$ & LME & $\mathrm{F}_{(3,76)}=2.0$ & 0.123 \\
\hline Vigilance (s) ${ }^{1,2}$ & $5.1 \pm 0.1(175.6)$ & $5.1 \pm 0.1(169.7)$ & $5.1 \pm 0.1(170.5)$ & $5.1 \pm 0.1(171.6)$ & LME & $\mathrm{F}_{(3,76)}=0.6$ & 0.30 \\
\hline Vigilance (mean rank) & $52.5 \pm 5.0$ & $33.2 \pm 4.5$ & $36.5 \pm 5.3$ & $39.9 \pm 4.9$ & Kruskal-Wallis & $X^{2}(3)=8.1$ & 0.04 \\
\hline Sniff photo $(n)^{1}$ & $1.0 \pm 0.1(2.7)^{\mathrm{a}}$ & $1.4 \pm 0.1(4.0)^{\mathrm{ab}}$ & $1.6 \pm 0.1(4.7)^{\mathrm{b}}$ & $1.1 \pm 0.1(3.1)^{\mathrm{a}}$ & GLME_P & $X_{(3)}^{2}=14.2$ & 0.016 \\
\hline Sniff environment $(n)^{1}$ & $0.0 \pm 0.4(1.0)^{\mathrm{a}}$ & $1.1 \pm 0.4(2.9)^{\mathrm{ab}}$ & $1.3 \pm 0.4(3.6)^{\mathrm{b}}$ & $1.0 \pm 0.5(2.7)^{\mathrm{ab}}$ & GLME_NB & $X_{(3)}^{2}=9.9$ & 0.02 \\
\hline Sniff closed window $(n)^{3}$ & 1 & 1 & 1 & 4 & FET & $\mathrm{N} / \mathrm{A}$ & 0.34 \\
\hline Zones crossed $(n)^{1}$ & $2.7 \pm 0.1(14.1)^{\mathrm{a}}$ & $2.9 \pm 0.1(17.9)^{\mathrm{a}}$ & $2.8 \pm 0.1(16.5)^{\mathrm{a}}$ & $3.5 \pm 0.1(32.7)^{\mathrm{b}}$ & GLME_NB & $X^{2}{ }_{(3)}=22$ & $<0.001$ \\
\hline Zones entered $(n)^{1}$ & $1.5 \pm 0.1(4.5)^{\mathrm{a}}$ & $1.7 \pm 0.1(5.1)^{\mathrm{a}}$ & $1.7 \pm 0.1(5.5)^{\mathrm{ab}}$ & $2.0 \pm 0.1(7.5)^{b}$ & GLME_P & $X^{2}{ }_{(3)}=17.2$ & $<0.001$ \\
\hline Standing near photo (s) & $102.8 \pm 16.5^{\mathrm{ab}}$ & $105.0 \pm 16.5^{\mathrm{a}}$ & $98.2 \pm 16.5^{\mathrm{ab}}$ & $70.4 \pm 16.5^{\mathrm{b}}$ & LME & $\mathrm{F}_{(3,76)}=3.3$ & 0.025 \\
\hline Enter zone close to $\operatorname{dog}(n)^{3}$ & $4^{\mathrm{a}}$ & $6^{\mathrm{ab}}$ & $7^{\mathrm{ab}}$ & $14^{\mathrm{b}}$ & FET & N/A & 0.009 \\
\hline Open-mouthed bleats $(n)$ & $0.7 \pm 0.5^{\mathrm{a}}$ & $1.5 \pm 0.6^{\mathrm{a}}$ & $3.3 \pm 1.2^{\mathrm{a}}$ & $16.5 \pm 2.6^{b}$ & GLME_NB_H & $X^{2}{ }_{(3)}=11.5$ & 0.009 \\
\hline Close-mouthed bleats $(n)$ & $2.8 \pm 0.6$ & $4.1 \pm 0.6$ & $6.0 \pm 0.9$ & $7.4 \pm 0.7$ & GLME_NB_H & $X_{(3)}^{2}=4.0$ & 0.26 \\
\hline Urinations $(n)^{3}$ & 7 & 3 & 2 & 4 & FET & N/A & 0.31 \\
\hline
\end{tabular}

a,b,c Different superscripts within rows indicate a significant difference between treatments as determined using post-hoc analyses, significant P values are 2 emphasized with bold font

$3 \quad{ }^{1}$ Least squares means are given on the log scale, back-transformed means are given in parentheses

$4 \quad{ }^{2}$ Vigilance duration was censored at $180 \mathrm{~s}$

$5 \quad{ }^{3}$ Raw number of animals of a total of 20 in each group are given

6 LME; linear mixed effects model fitting test day as a random effect, GLME; generalized linear model with a Poisson (P) or Negative Binomial (NB) distribution, 7 data including excess zeros used hurdle models (H), FET; Fisher's Exact Test was used to calculate probability, test statistic is not applicable (N/A), post hoc 8 analyses were performed using the package rcompanions 


\section{Table 3(on next page)}

Hazard ratios for latency to sniff the photo, sniff the environment and become nonvigilant as affected by treatment group. 


\begin{tabular}{|c|c|c|c|c|c|c|c|c|c|c|c|}
\hline Latency to & Group & $\operatorname{Mean}(s)^{1}$ & Censored $(n)^{2}$ & Coefficient $^{3}$ & SE (coeff) & Hazard ratio $^{4}$ & Wald (z) & $\mathbf{P}$ & Likelihood Ratio & df & $\mathbf{P}$ \\
\hline \multirow{9}{*}{ Sniff photo } & Control & $19.1^{\mathrm{a}}$ & 1 & Reference & & & & & \multirow{9}{*}{18.4} & \multirow{9}{*}{3} & \multirow{9}{*}{0.001} \\
\hline & Anxious & $65.7^{\mathrm{b}}$ & 4 & -1.188 & 0.36 & $0.31(0.15-0.62)$ & -3.3 & 0.001 & & & \\
\hline & Calm & $16.4^{\mathrm{a}}$ & 0 & -0.095 & 0.33 & $0.91(0.48-1.73)$ & -0.29 & 0.772 & & & \\
\hline & Happy & $18.9^{\mathrm{a}}$ & 0 & -0.299 & 0.33 & $0.74(0.39-1.43)$ & -0.89 & 0.372 & & & \\
\hline & Anxious & & & Reference & & & & & & & \\
\hline & Calm & & & 1.093 & 0.35 & $2.98(1.49-5.97)$ & 3.09 & 0.002 & & & \\
\hline & Happy & & & 0.889 & 0.35 & $2.43(1.23-4.81)$ & 2.56 & 0.010 & & & \\
\hline & Calm & & & Reference & & & & & & & \\
\hline & Happy & & & -0.204 & 0.32 & $0.816(0.44-1.53)$ & -0.63 & 0.526 & & & \\
\hline \multirow{9}{*}{$\begin{array}{l}\text { Sniff } \\
\text { environment }\end{array}$} & Control & $102.4^{\mathrm{a}}$ & 5 & Reference & & & & & \multirow{9}{*}{20.5} & \multirow{9}{*}{3} & \multirow{9}{*}{$<0.001$} \\
\hline & Anxious & $147.3^{\mathrm{b}}$ & 12 & -1.189 & 0.44 & $0.3(0.12-0.72)$ & -2.69 & 0.007 & & & \\
\hline & Calm & $102.5^{\mathrm{a}}$ & 8 & -0.256 & 0.39 & $0.77(0.36-1.65)$ & -0.66 & 0.510 & & & \\
\hline & Happy & $91.2^{\mathrm{a}}$ & 4 & 0.128 & 0.36 & $1.13(0.56-2.3)$ & 0.35 & 0.723 & & & \\
\hline & Anxious & & & Reference & & & & & & & \\
\hline & Calm & & & 0.934 & 0.46 & $2.54(1.03-6.27)$ & 2.03 & 0.043 & & & \\
\hline & Happy & & & 1.317 & 0.44 & $3.73(1.58-8.82)$ & 3 & 0.003 & & & \\
\hline & Calm & & & Reference & & & & & & & \\
\hline & Нарру & & & 0.384 & 0.38 & $1.46(0.69-3.11)$ & 1 & 0.317 & & & \\
\hline \multirow{9}{*}{$\begin{array}{l}\text { Non- } \\
\text { vigilance }\end{array}$} & Control & $65.5^{\mathrm{a}}$ & 2 & Reference & & & & & \multirow{9}{*}{19.3} & \multirow{9}{*}{3} & \multirow{9}{*}{$<0.001$} \\
\hline & Anxious & $132.9^{\mathrm{b}}$ & 11 & -1.522 & 0.42 & $0.21(0.09-0.49)$ & -3.65 & 0.000 & & & \\
\hline & Calm & $99.0^{\mathrm{a}}$ & 5 & -0.671 & 0.35 & $0.51(0.25-1.02)$ & -1.9 & 0.058 & & & \\
\hline & Happy & $100.2^{\mathrm{a}}$ & 6 & -0.674 & 0.36 & $0.51(0.25-1.02)$ & -1.88 & 0.060 & & & \\
\hline & Anxious & & & Reference & & & & & & & \\
\hline & Calm & & & 0.851 & 0.42 & $2.34(1.02-5.37)$ & 2.01 & 0.044 & & & \\
\hline & Happy & & & 0.848 & 0.43 & $2.33(1-5.43)$ & 1.97 & 0.049 & & & \\
\hline & Calm & & & Reference & & & & & & & \\
\hline & Happy & & & -0.003 & 0.37 & $0.99(0.48-2.06)$ & -0.01 & 0.993 & & & \\
\hline
\end{tabular}

$1 \quad{ }^{1}$ Raw mean latencies are given, superscripts indicate significant differences between groups for each behavior

$2{ }^{2}$ Number of animals which failed to exhibit the given behavior within $180 \mathrm{~s}$ were deemed as censored results

$3{ }^{3}$ Regression coefficient from the Cox-proportional hazards model

$4 \quad 495 \%$ confidence interval given in parentheses 